\title{
FAMILIA Y EDUCACIÓN EN CUATRO REPRESENTANTES DE LA GENERACIÓN DE 1936: LAÍN ENTRALGO, JULIÁN MARIAS, JULIO CARO BAROJA Y FRANCISCO AYALA
}

\author{
POR \\ José Manuel Cuenca Toribio \\ Soledad MiRAnda Garcia \\ Universidad de Córdoba
}

\section{RESUMEN}

En este artículo se analiza la infancia y educación de estos cuatro escritores de la generación de 1936 por medio de sus relatos biográficos, intentando fijar la importancia de la misma en su producción y formas de comportamiento posteriores.

\section{Abstract}

This essay analise the childhood and educational period of these 36 Generation's four writers trhough their biographies, trying to fix the importance of these aspects in their literature and later behaviours.

Junto con su bien merecida celebridad en el cultivo de múltiples disciplinas pero señaladamente en el género proteico e híbrido denominado ensayo, la gavilla de nuestro autores ofrece semejanzas muy destacadas. No podía ser, claro está, de otra manera, dada su común inclusión a la última de las generaciones intelectuales españolas de gran irradiación y sólida consistencia.

Pero al hablar aquí de estos vínculos nos queremos referir en especial a componentes sociales y también, en cierta medida, psicologicos. Su nítida pertenencia al estamento burgués es quizás, en tal orden de cosas, la más so- 
bresaliente. Una burguesía que en casi todos los casos se enraíza y colinda con las clases medias, sobre todo, lugareñas, pero que tiene muy asumidos sus valores y objetivos; proyectándose éstos en el ejemplo que nos ocupa al mantenimiento del status más que a su acrecentamiento por vía económica. Las inquietudes o al menos la sensibilidad hacia el mundo de la cultura y el espíritu será muy viva en todos los hogares en que nacieron los escritores aquí glosados. Al leer las páginas dedicadas a la niñez en sus autobiografías y recuerdos se observa claramente que la atmósfera intelectual que se respiraba en aquéllos no era menos densa al tiempo que porosa que la de los escritores franceses o británicos contemporáneos provenientes de idéntica cepa social.

El amor al estudio, la libido sciendi más que como instrumento o peldaño de ascenso social, como satisfacción de anhelos íntimos, será también otro de los rasgos unificadores que indicábamos más atrás. Si el creador, con estatuto científico, de los estudios de la historia de la medicina española, Pedro Laín (Urrea de Gaén [Teruel], 1908), confiesa que no fue nunca un estudiante "pigre" - dos licenciaturas antes de los veinte años bien lo patentizan-, el más autocomplaciente de todos ellos, Julián Marías (Valladolid, 1914), relatará, con gusto por el detalle, sus hazañas estudiantiles antes de traspasar la primera gran frontera de la vida - el cabo de los diez años. Más recatado, pero no menos puntual en esta información, el único madrileño de nuestro elenco, pondrá de relieve los numerosos hilos culturales que se hilvanaban en el cadejo familiar, precozmente manejado por él; y, en fin, con cierto complejo edípico, Francisco Ayala (Granada, 1906) no ahorrará tampoco espacio para dejar constancia de su temprana conciencia de continuador de la estirpe intelectual representada por su madre, mujer de tremente sensibilidad y amplitud de lecturas, gustos heredados, junto con sus hermanos, de su padre, el afamado rector y médico granadino don Eduardo García Duarte. Matrículas de honor y distinciones académicas se acumularán así en los expedientes escolares de los más metódicos de nuestros autores, sin que los menos reglados - Julio Caro Baroja (Madrid, 1914) y Francisco Ayala-- fueran, no obstante, a la zaga a la hora de acumular conocimientos y saberes en edad muy temprana ${ }^{1}$.

Ante tal panorama ya se columbra fácilmente que el mundo familiar de nuestros autores debió presentar un ambiente, en general, feliz y estimulante. Y así fue. Todos nos hablan, incluidos los más "contestatarios" -y nuevamente Caro Baroja y Ayala integran pareja-, de unos primeros pasos por la vida presididos por el signo de la plenitud. Sus respectivos padres formaban matrimonios muy unidos -algo menos también en la pareja antecitada-, identificados en vigencias sociales y metas y, naturalmente, muy acordes res-

1 P. LAIN, Una y diversa España. Bercelona, 1968, 160-161. J. MARIAS, Una vida presente. Momorias I (1914-195I). Madrid, 1988, 37-38.

Aficiones y devociones en el antiguo régimen

Hispania Sacra 50 (1998) 
pecto a los principios de la formación de su descendencia. Tanto en el hogar - "medio burgués, medio campesino"-, según define Laín Entralgo a la casa de un médico rural,como la de un alto empleado vallisoletano, en la de un impresor madrileño o en la de un hacendado granadino, la existencia en la ya remecida España de los años diez, transcurrirá plácida y alentadoramente para la grey infantil. Pronto - será el caso de Marías y de Ayala - las holguras económicas amenguaron bastante, surgiendo problemas materiales donde no los había, pero el estricto perímetro de la niñez de los escritores ahora glosados estuvo enseñoreado por la alegría y la bienandanza. A confesión de parte, hemos de creer que ésta depositó en el fondo de sus espíritus algunas de sus convicciones mas profundas; entre ellas, la de la fe en el progreso así como una concepción, en conjunto, antihobbesiana de la vida ${ }^{2}$.

Infancia, desde luego, enriquecedora socialmente. Incluso en los de ego más peraltado o de mayor propensión al hermetismo, el tipo de familia extensa que entonces caracterizaba a esta institución en nuestro país determinaría su madrugador contacto con personas y mundos muy diversos. Pese a que los progenitores de algunos de ellos -en concreto, los de Marías y Caro Barojano cotizaban altamente la consanguineidad, ni vieran en la gens ni en la "sangre" temas tabues o ancestrales, es lo cierto que todos nuestros autores, cuando niños, se codearon y aproximaron a las infinitas peripecias encarnadas en la vida y milagros de deudos y parientes; muchos de los cuales arrojaron sombra benéfica sobre sus andanzas pubertales y formación moceril. Paisajes físicos y psíquicos de muy vario tenor se fotografiaron así por espíritus casi hiperestési$\cos$, conformando capas esenciales de su textura anímica e intelectual ${ }^{3}$. Acorde

2 "En nuestra casa la vida era apacible. Mis padres se llevaban muy bien, no se peleaban nunca, creo que se querían entrañablemente; mi tía Araceli, no muy alegre, más bien silenciosa, era afable y se sentía parte total de la familia; mi hermano y yo también teníamos una relación sumamente amistosa. Vivíamos con holgura; no éramos ricos, pero teníamos algo más de lo necesario; y bastante consideración social". Una vida..., 21. F. AYALA, Recuerdos y olvidos. Madrid, 1982, 28-29.

3 "Así como mi familia paterna fue un clasico ejemplo de familia burguesa en decadencia, mifamilia materna puede considerarse como modelo de familia burguesa rara, según el módulo español o de cualquier parte. Raros en el aspecto, raros en las ideas, raros en los usos y costumbres. Esto lo decían en Madrid muchas personas, allá a comienzos de siglo. Por un lado, mi abuelo pertenecía a una clase distinguida de técnicos; era ingeniero de minas y como tal la generalidad de la gente lo consideraba hombre de bastante categoría. Si piensa uno en la cantidad de ingenieros vascos que han pululado y pululan por Espafia, desde la fundación de las escuelas especiales hasta hoy, podria pensar que se trataba de un señor de aplastante vulgaridad, casado con una señora rica y beata y con unos niños y niñas educados por los jesuitas y en el Sagrado Corazón, respectivamente. Pero mi abuelo no era del mismo paño que muchos de sus colegas vascos. No tenía más dinero que el que le producía un sueldo del Estado; su mujer era una mujer religiosa, pero poco clerical [...] En el ambiente propio de la burguesía madrileña finisecular o de "avant-guerre" mi farnilia matema, compuesta por mis abuelos, mi madre y mis dos tíos, se salía escandalosamente de las normas. Desarraigados una y otra vez, a causa de las andanzas de mi abuelo, vivían formando un núcleo compacto, bastante al margen de la 
con su condición de antropólogo (probablemente deseada al calor de una familia plural y densa, absorbente y liberal), será Julio Caro Baroja el que trace una pintura más completa de su genalogía próxima. Tanto por parte de los Caro como de los Baroja, los últimos capítulos de la saga estarían poblados de tipos que semejan extraídos en su gran mayoría de las novelas más exóticas del XIX y aún de sus mismos folletines - los abuelos, las tías paternas, el inclasificable D. Pío...-, junto, como decimos, con una hormigueante y a menudo estrambotica parentela. Exotismos aparte, Caro Baroja, al describir, con expensas, el profuso censo de sus deudos proporciona uno de los cuadros más acabados que acerca de la familia burguesa posee la literatura y la bibliografía españolas. Sin fe ni simpatía por ella es claro que esta galería de semblanzas no se hubiera acometido por un autor que disfruta, con legitimidad incontestable, de fama de atrabiliario y mercurial en la república de las letras.

En estos niveles de la burguesía ilustrada del primer tercio del siglo XX se constatará que la noción y representación de España era plural,. La fluidez y la comunicación se presentaban como elementos constitutivos de un árbol genealógico muy ramificado y de una posición material desde la que era fácil el acceso a toda clase de bienes culturales. La historia familiar, tan cultivada entonces oralmente y, de manera más ocasional, documentada y literariamente, se manifestaba de este modo como fácil medio para acceder a una historia nacional, erigida en eje vertebrador de la formación escolar, con una lectura tanto familiar como académicamente enfática y, a menudo, orgullosa ${ }^{4}$.

En la sociedad heril cuyos últimos reflejos acotara el mundo de la infancia de nuestro escritores, criados y criadas, integrados de ordinario en el tejido familiar, ponían otra nota polícroma a esta visión de una España diversa y, al propio tiempo, a la formación de los niños y niñas de los hogares a los que se incorporaban. Con excepción de Laín, los intelectuales de que nos ocupamos en estas páginas dejarán constancia no sólo de la proliferación y abundancia de dicho estrato en los hogares burgueses de la época, sino también de la deuda

\footnotetext{
vida corriente de la capital". J. CARo BAROJA. Los Baroja (memorias familiares). Madrid, 1972, 4243. "Hijo de médico y descendiente por ambas ramas de familias mesocráticas de la provincia espanola -mi abuelo paterno, médico en Huesca; mi abuelo materno, militar retirado en una villa de La Rioja alavesa, tras varios años de guamición en Cuba". P. LAIN ENTRALGo. Descargo de conciencia (1930-1960). Madrid, 1976, 14-15. "Mi padre, nacido en Alcolea de Cinca, Huesca, en 1870, había vivido alli nueve años; sus padres, Benito Marías Puértolas y Pascuala Sistac Baringo, eran maestros de ese pueblo; mi abuelo, abogado, fue secretario de su Ayuntamiento..." Una vida..., 18. F. AYALA, Recuerdos $y$..., 26 y ss.

4 El ejemplo de Marías puede mirarse en la cuestión aludida a la luz de una cierta salvedad; "Mi padre tenía muy poca relación con sus hermanos y sobrinos. Mi madre tenía un sentido familiar mucho más fuerte -.."es de mi sangre", decía a veces-; yo, que me parecía fisicamente más a mi madre que a mi padre, no heredé este rasgo". Una vida..., 31-32.
}

Aficiones y devociones en el antiguo regimen

Hispania Sacra 50 (1998) 
contraída con varios de ellos en punto a su educación integral. Un lugar privilegiado y extenso de sus memorias lo ocuparán amas de cría, servidores y servidoras domésticos; hasta el extremo de que Marías no vacilará en desplegar un mínimo ensayo acerca de las causas del álgido ocaso de tal estamento y que Caro Baroja entonase entusiastas loas a las nodrizas y criadas trasplantadas de sus caseríos vascos a la metrópoli madrileña, a la que nunca acabarían por adaptarse, permaneciendo fieles, a través de canciones y leyendas, a las verdes praderías de su niñez; sin que, por su parte, Ayala, siempre más esculcador de los bajos fondos sociales y anímicos, renuncie a desarrollar también una teoría sobre las artes celestinescas y los ritos iniciáticos a la sexualidad impartidos con maestría por algunas criadas granadinas...5.

Habida cuenta de su extracción burguesa, niñez y primeras letras se hermanaron. Unos en los propios hogares - madre, padre, tía o tío, viudos y solteros, convertidos en sustitutos del maestro-, otros en las escuelas y colegios, velaron estas armas con indudable aprovechamiento. Muy pronto, como dijimos, su espíritu despertó a la cultura como vivencia suprema y bien anhelado con ardimiento. En los más juniores -Marías y Caro-dicha andadura coincidió con los últimos años de la Gran Guerra y, por ende, con un creciente dinamismo de la sociedad hispana, atravesada por impulsos y tensiones creadores en cualesquiera de sus manifestaciones. Ellos y sus compañeros mayores - Ayala y Laín - sorbieron con fruición los nuevos vientos, conscientes, sin duda por vía de intuición, de que los acontecimientos objeto de recurrente referencia en conversaciones y pláticas familiares marcaban una línea divisoria en la marcha de la humanidad. Frente a las generaciones más domésticas y nacionalistas procedentes, estos escritores, y otros también pertenecientes a su hornada generacional, mostrarían una superior atención al manejo de lenguas extranjeras y a los problemas y corrientes, culturales o no, del ancho mundo. Apertura

5 "Pero quería decir antes unas palabras de las muchachas de servir de mi niñez. Por lo general eran chicas de pueblo, muy jovenes; mi madre las trataba maternalmente, se ocupaba de ellas, se preocupaba por cllas; casi todas la adoraban. Mi hermano y yo nos llevábamos muy bien con estas chiquillas, asábamos con ellas en la cocina castañas y patatas, les enseñanos lo que sabíamos: a leer, a escribir [...] Nada hay más desprestigiado y condenado que el servicio doméstico; sin duda, era muchas veces antipático, abusivo, explotador, casi una guerra larvada. Recuérdese, aunque descontando el humor y la caricatura, La Gran Via. Pero representaban un mecanismo de educación, de educación de lo rural a formas más refinadas. Las chicas aprendían muchas cosas, sobre todo las destrezas dométicas que necesitarían después; adquirían cierto pulimento; hablaban mejor; ahorraban algún dinero para casarse. Todo eso se fue perdiendo, hasta conseguirse que ninguna chica quisiera el servicio doméstico.Se dirá que la industrialización fue decisiva. Ciertamente, pero también lo que se dice - nunca se exagerará la influencia de la palabra-; en cierto momento que no puedo precisar, los chicos, sobre todos los estudiantes, empezaron a llamar a las criadas "marmotas". Creo que fue decisivo." Una vida ,.., 40-41. 
que, conforme la declaración de alguno, sería muy consciente y sostenida apenas transpasada la niñez ${ }^{6}$.

Transcurrida ésta, la segunda enseñanza se le enfrentaba. Pero, en oposición a la mayor parte de los que afrontan tal trance, el Bachillerato no se le ofrecía a manera de riesgo o desafio como no fuera el de abrillantar la fama de estudiosos que les distinguía entre sus familiares y amigos. Si, con la salvedad, por lo demás, parcial, de Ayala, los años escolares no habían dejado en ellos malos recuerdos, igual sucedería con los de la enseñanza secundaria. Esta fue cursada en todos los casos en Institutos, excepto por Caro, que lo haría en el célebre Instituto-Escuela madrileño, acogido, como se sabe, a un régimen mixto oficial-privado ${ }^{7}$. El curriculum de Pedro Laín presenta la particularidad de haber seguido sus enseñanzas, con máximo aprovechamiento académico, en cuatro centros: el Instituto de Soria, el de Teruel, el de Zaragoza y el iruñés. La razón se encuentra en el hecho de haber estudiado bajo la tutela de su tío -marido de la hermana de su padre-, médico y profesor sin hijos y amante de la movilidad y trasiego burocráticos. Ciertamente, ese asendereado bachillerato pone el único rasgo singular en una formación caracterizada por su rigor y excelencia. En conjunto, los establecimientos de enseñanza media oficiales gozaban entonces de una notable reputación en la opinión pública debido a la competencia y puntual cumplimiento de sus deberes por la mayor parte de sus cuadros docentes, beneficiados por la reforma educativa finisecular. Lejos de cualquier panfilismo, los juicios sobre sus maestros y profesores de aquella etapa son en nuestros autores muy positivos, aunque el radiante cuadro cobre, según es natural, más autenticidad con la pintura en noir de alguna disciplina y de uno o varios docentes, sobresaliendo en tal terreno la aristarca pluma de Caro Baroja. $\mathrm{Al}$ reconstruir sus años bachilleriles o al hacerlo Ayala de su adolescencia, transcurrida académicamente en el granadino, describen un capítulo de la historia educativa que nos hace ver cómo era éste uno de los ligámenes más fuertes que nos unía a los restantes pueblos occidentales y revelador de una de las

\footnotetext{
6 Ibidem

7 "Dejando a un lado unos días que fui a una escuela de barrio cerca de casa en Madrid, de ftailes de babero blanco, que eran gente buena, pero que se marchó, y otros pacos en que olfaté lo que pasaba en la Escuela de los Escolapios, durante una primavera en Vera, desde el año 21 al 31 fui al mismo centro de enseffanza: el Instituto-Escuela [...] El Instituto-Escuela de Madrid era un centro pedagógico con mucho prestigio. Se había fundado como algo con carácter experimental, para dar la primera y segunda enseñanaza a niños y muchachos de familias madrilef́as, burguesas y con ciertas aspiraciones o pretensiones intelectuales. Yo creo que fue un excelente sitio para educar a los párvulos y para los niños que estudiaban el preparatorio de bachiller. $Y$ aunque como instituto de segunda enseñanza superaba en mucho a todos los de su época, me parece que con relación a ella no estuvieron sus creadores tan afortunados como en la primera enseñanza". Los Baroja..., 157
}

Aficiones y devociones en el antiguo régimen

Hispania Sacra 50 (1998) 
muestras más claras de la modernización por la que, a trancas y barrancas, se adentraba el país ${ }^{8}$.

Religión, Historia y las asignaturas concernientes a las Ciencias "puras", en el lenguaje de nuestra-léxicalmente-bárbara época, nucleaban la formación impartida en los centros a que asistieron nuestros biografiados, a modo de símbolo elocuente de las tres concepciones del universo que se disputaban aún la primacía en los entendimientos y credos políticos y filosóficos. A pesar de la secularización que ganaba terreno en los ambientes ilustrados a que pertenecían nuestros autores,sus escritos memoriográficos no dejan duda sobre la importancia que la cuestión religiosa $\mathrm{y}$, más concretamente, el catolicismo, poseía en todo el ámbito de la sociedad española. Bien que alguno de sus padres manifestasen un tibio sentimiento religioso que llegaba a rozar, en ocasiones, las fronteras de un mesurado anticlericalismo (—así, el padre de Laín hacía honor a las mejores tradiciones del. estamento galénico progresista y el de Caro no desdoraba los blasones del más candoroso doceañismo y hasta el más recatado en estas expresiones anticlericales, el de Marías, dejase de ir a la misa dominical por mor de ciertos achaques físicos-), la atmósfera hogareña estaba penetrada en esencias religiosas, algunas de rancio cuño, debido a que era éste un dominio en el que las mujeres imponían sin réplica alguna marital la observación más estricta de cultos y liturgias ${ }^{9}$.

8 "El Instituto, al que en un principio se habían resistido mis padres a enviarme, considerando sin duda que dejaba en demasiada soltura a los chicos, fue para mi, de todos los establecimientos docentes por los que había pasado, el que más a gusto me hizo sentir. De los dos colegios de monjas, el de Niñas Nobles y el de Calderón, donde me tuvieron antes de empezar el Bachillerato, ya he referido algunas anécdotas que aún escuecen en mi recuerdo. Esas quemaduras se destacan sobre un fondo gris de aburrimiento, de fastidio, de impaciencia reprimida [...] De otros profesores tambien excelentes, y de algunos pintorescos, podría decir bastante, pero no quiero extenderme más. Baste repetir que mi paso por la segunda enseñanza en el Instituto de Granada, corresponde a un periodo de mi vida marcado en el recuerdo por la sensación de una creciente plenitud". Recuerdos y..., $48-49$ y 56 .

9 "En definitiva, la familia en cuanto grupo social nunca quedaba fuera de la jurisdicción eclesiástica, ya que la vinculaban a ella no sólo las devociones femeninas sino también las ceremonias del bautizo, matrimonio y entierto, a que raramente se sustraían los varones por más reservas que tuvieran acerca de su significación trascendental; el social que indisputablemente ostentaban bastaba para obligarlos. Mi madre, criada dentro de un ambiente đoméstico laicista, agnóstico y anticlerical, se consideraba a sí misma católica sin la menor sombra de duda; y recuerdo -es un recuerdo que me apesadumbra- las torturas que a veces llevê yo a su ánimo cuando, siendo ya estudiante, hablábamos de religión, y, con la vehemente pedantería de los pocos años, le demostraba que algunas ideas suyas no eran ortodoxas, antes bien, tendían a coincidir con las posiciones del protestantismo. Lo cierto es que su religiosidad era muy pura. Infiemo o no infiemo, resurrección de la carme o no, mi madre era Io que puede propianente llamarse un alma cristiana". Ibid, 30. "La suma atracción de nuestra nueva casa estaba constituída para mi por una señora joven, verdaderamente encantadora, Luz Duarte, hija y hermana de los médicos de casa [...] Era una mujer singular por su inteligencia y cultivada sensibilidad”. M. FernandeZ Almagro, Viaje al siglo XX. Madrid, 1962, 207. " Mi padre, vehemente y 
De manera opuesta a gran parte de sus coetáneos, los escritores ahora comentados no encontraron en los cursos profesados en sus centros razones para fomentar un anticlericalismo unido muchas veces a la edad de las rebeldías. Globalmente, sacerdotes y canónigos impartieron con gracia y liberalidad las ciencias sagradas, que, académicamente, se ofrecían como optativas. A pesar del ambiente tradicional que, sobre todo, por parte paterna, regía en su casa, fue quizás Ayala el de más precoces actitudes anticlericales; a causa, en particular, según describirá con puntualismo miniaturista, de sus sonados rifirrafes de la niñez con las monjas francesas de su primer colegio. Tanto Laín como, de forma muy particular, Marías, no desplazarían sus posiciones religiosas en ninguna etapa posterior de la zona en que se asentaran en la niñez y adolescencia, mientras que el agnosticismo de Caro, respetuoso en todo momento con la religión tradicional de su país, estaría, por conducta deliberada, en los antípodas de un ateísmo militante o ni tan siquiera ateneístico ${ }^{10}$.

Según es bien sabido, la Historia gozaba en toda la enseñanza de la época de una gran presencia. Su puesto relevante era atribuído al mismo tiempo por las autoridades docentes y la atención de la sociedad, que vería en ella un saber medular para la organización política y la cultura de un país. No quedaron muy defraudados como alumnos de Clio nuestros autores pese a la hipermemorización y al patriotismo con ribetes grandilocuentes que sombreaban, de ordinario, cursos, programas y explicaciones. La afición por la Historia de los escritores analizados en las presentes páginas provenía ya, como la mayor parte de las vocaciones y deseos intelectuales, del propio hogar; siendo al respecto muy reveladoras las confesiones de Laín sobre el gusto de su padre por dicha disciplina, que pretendió inculcar, con rotundo éxito, en el mayor de sus

\footnotetext{
generoso, era un liberal republicano con toques de socialista a lo Pablo Iglesias; y aunque no iba a misa --"los que van a misa" y "los que no van a misa", dos ineludibles categorias sociológicas en la España de entonces-siempre mantuvo la mejor rełación con los curas del pueblo; uno de ellos, Laín como nosotros, mas no pariente nuestro, me dio en su despacho lecciones de gramática latina cuando empecé el Bachillerato. Mi madre, mujer muy duice y bondadosa, fue católica sincera y como tal pudo conducirse en la vida local hasta el mismo día de su muertc. Mis dos hermanos y yo, educados según las normas habituales en el lugar, íbamos a misa y en la Iglesia aprendimos el catecismo; luego, naturalmente, cada cual siguí́ su propio camino". Descargo de conciencia..., 16. "También me alegro de que mi familia (siguiendo el criterio de mi abuela, apoyada por mi madre), me hiciera estudiar Religión en el Instituto". Los Baroja..., 161. "Tenía espiritu religioso, pero era anticlerical inofensivo, al uso de los republicanos de entonces; poco practicante, iba a misa los domingos con su mujer y sus hijos, y andando el tiempo se fue acostumbrando a quedarse en la cama, porque dormía mal por las noches [...] Mi madre [era] profundamente religiosa, sin la menor beatería pero con una fe sólida y compacta, vivida con naturalidad y sin gazmofieria ni intolerancia". Una vida ..., 30-31.

10 Muy curiosa es la salvedad de Marías: "La clase de religión era voluntaria -no se olvide que estamos en tiempos de la Monarquía y de la Dictadura-; tenía fama de no ser muy interesante; no asistí a ella, y acaso por eso he conservado mi fe intacta y viva". $I b i d, 61$.
}

Aficiones y devociones en el antiguo régimen

Hispania Sacra 50 (1998) 
hijos, entusiasta lector infantil de la célebre Historia del Consulado y el lmperio, de Adolfo Thiers. Al hablar de los primeros años de la fecunda existencia de Caro Baroja no puede eludirse en ningún instante la alusión a su tío, ya que el famoso novelista vivía en el hogar de sus padres, proyectando un decisivo influjo sobre la educación sentimental e intelectual de su sobrino predilecto. Don Pío reforzó una acezante curiosidad brotada quizás al calor de los relatos de amas y de ayas así como de su abuela materna y padres. El bachillerato ahincó en él una inclinación por la Historia nunca desmentida.Marías, siempre adelantado según su testimonio, manifestado habitualmente con latitud, quedó imantado por la Historia con sus repasos de las monumentales revistas de actualidad que recogían en detallados reportajes gráficos los avatares de la guerra europea. Y, finalmente, Ayala asistió en reizamiento de la semilla sembrada en su lábil imaginación por las consejas y relatos oídos al calor de la lumbre, mientras sobre la ciudad del Darro caía la nieve..."

Pero más allá de las peripecias historiográficas bachilleriles de los autores aquí glosados, se hace obligado anotar que aficiones y estudios conformaron todos una conciencia histórica muy alertada, convertida en auténtico foco de su personalidad científica y en motor de la humana. En el cruce de una a otra década a ninguno le pasaría inadvertida no ya la crucial experiencia de la primera guerra mundial, sino los tiempos revueltos que presidirían por mucho tiempo los destinos de su país, incluso bajo la calma superficie de la primera dictadura. La Historia, hasta entonces saber académico, iba a transformarse, en su espíritu y en el de sus coetáneos, en saber existencial.

Claro está que en cuanto a directrices académicas y en el propio campo de la opinión pública las ciencias experimentales contendían ya de forma clara vez más favorable con el primado educativo de la Historia. Por contra, en España, el camino hacia la modemización por el que apostaban decididamente casi todos los padres de nuestros autores y los ambientes por ellos frecuentados, pasaba por la adopción entusiasta de los métodos y técnicas que labrasen el auge y la supremacía de las naciones más adelantadas del planeta. No es de extrañar, pues, que tanto ellos - Laín se doctoraría a la par en Química y en Medicina - como sus catedráticos y profesores de dichas materias colocaran muy alto el prestigio y la necesidad de adquirir una instrucción muy completa en saberes mirados todavía por ciertos sectores como arcanos.

Rasgo destacado de la formación intelectual de la generación a que pertenecen los escritores aquí comentados es la asunción del freudismo como una de las grandes conquistas científicas del siglo. Aunque ninguno mostrara una

11 Una y diversa ..., 146. Acerca del surgimiento de la vocación historiografica del autor de $L$ os judlos en la España moderna y contemporánea, vid J.M. CUENCA TORIBIO, "Caro Baroja, historiador de España" en Intelectuales y políticos contemporáneos. Sevilla 1998, 107-19. 
inclinación particular por los principales extremos de la teoría del psiquiatra vienés, ninguno también, claro es, dejará de constatar su importancia para el conocimiento de una gran parte de la vida afectiva y, en general, de la conducta humana. Por ende, no sorprenden que consagren una buena porción de sus páginas memoriográficas al "despertar de la pubertad". Con precisión y finura, Laín Entralgo buceará en sus recuerdos de asombrado niño pueblerino y, más tarde, capitalino - bien que de una urbe de rango menor, pero no por ello menos capital de provincia: Soria-, para repescar sus actitudes iniciales ante el fenómeno sexual; primero, en la zoología y muy poco más tarde en el encuentro con muchachas en flor... Por lo que respecta al autor de Muertes de Perro, ya hemos hablado de los violentos altercados mantenidos en plena infancia con sus educadoras, monjas espantadizas y quién sabe si educadas, como francesas, en la tradición de Port Royal. Conviene ahora aclarar que estos enfrentamientos tuvieron primordialmente una motivación algo escabrosa por parte de un chico que durante todo el bachillerato no desmentiría su curiosidad por el tentador mundo de la sexualidad, ante el cual, por lo demás, según declaración propia, su postura y comportamiento se acomodaría a la normalidad.

También los juniores de nuestro grupo hablarán del tema, pero de manera, en conjunto, algo más restrictiva e impersonal. Hay que decir, sin embargo, que tanto Marías como Caro Baroja valorarán sumamente la educación que regía en los centros de enseñanza primaria y secundaria a que concurrieron, estimándola la más adecuada para la formación integral de los jóvenes ${ }^{12}$.

12 "La coeducación, sisterna que se seguía en el Instituto-Escuela durante la primera enseñanza elemental y luego al hacerse la separación de los bachilleres de letras y de ciencias, para los de letras, creo que tiene la ventaja de acercar a hombres y mujeres y darles ideas mucho menos esquemáticas acerca del sexo contrario que las que tienen si se les educa aislados. Evita también, hasta cierto punto, la animosidad recíproca que luego estalla en forma amorosa [...] Desde luego, la coeducación tiene algo que ver con el desarrollo de los instintos sexuales de los niños y adolescentes. Pero no tanto como decían en un tiempo sus detractores católicos [...] E] despertar a la vida sexual es lento y enojoso. Y creo evidente que las experiencias primeras, sunconscientes, son muy tempranas y relacionadas con la vida erótica de los padres. En las fanilias de gente muy pobre la promiscuidad produce resultados tremebundos según es bien sabido. En la burguesía no se da tanto la promiscuidad. Pero no creo que las familias espanfolas, en general, se ocupen de modo inteligente de reglamentar las relaciones de padres e hijos, para obtener un resultado determinado. Mal o bien sale lo que sale [...] Mi abuela consideraba "tabú" todo lo que se refiriera al sexo y así viví hasta muy crecidito en mi categoría de "niño", como si fuera algo puro, cristalino, que puede mancillarse si se toca demasiado. Mi madre le dejaba hacer. Pero como yo no era un niño tonto, tampoco fui tan inocente como mi buena abuela créa, aunque si acaso más que la generalidad de los nin̄os españoles". Los Baroja..., 171-173. "Pocas veces se hablaba en su tertulia de temas escabrosos sexuales, aunque de viejo le gustaba hablar de amor como de algo fundamental en su vida. Este pudor fue también probablemente el que le hizo demostrar varias veces, de un modo violento, su adversión a las teorías psicoanalíticas de Freud y el que hacía que en casa se considerara como de mal gusto el tratar de "cosas personales". Semblanzas ideales. Madrid, 1972, 33.

Aficiones y devociones en el antiguo régimen

Hispania Sacra 50 (1998) 
Hombres de su tiempo, mostrarían en la niñez y adolescencia una fuerte atracción por los inventos descubiertos o realizados coetáneamente a su venida al mundo o popularizados durante su edad infantil, a manera, v. gr., de la aviación o del cine. El séptimo arte gozó, desde luego, en sus preferencias de un lugar descollante. Así Laín describiría honda y bellamente el impacto de la película semanal en los sorianos endomingados, con los que se apretujarían espíritus trementes, como los del propio autor. Es curioso, no obstante, que un escritor como Marías, cinéfilo sobresaliente (acaso el que más, entre todos los pensadores españoles del novecientos) nos hable más de la sugestión del tren que del cine sobre su imaginación infantil, tal vez por un prurito de originalidad. Lo cierto es, con todo, que el ferrocarril seguía aún simbolizando en España, en la mente de niños y mayores, el santo y seña de la modernidad, la materialización de los más grandes sueños del hombre y el motor más activo de las fantasías individuales y colectivas ${ }^{13}$.

Conforme expusimos más arriba, la Guerra Europea señaló en todos estos niños precoces - un mozalbete hecho y derecho en el caso de Ayala- una intuición de ruptura con la sociedad precedente. Llegados los "felices veinte" todos tendrían la conciencia de estar asistiendo al verdadero nacimiento del siglo XX, del que, siguiendo el consejo de una personalidad admirada por todos ellos, Gregorio Marañon, serían grandes patriotas, sin desconocer, por supuesto, sus taras y sombras. Acabados los estudios universitarios en el ejemplo de los seniores, iniciados los de los juniores, en el umbral de la década de los treinta, todos experimentaran la misma sensación. Con la terminación de la dictadura primorriverista se ha vuelto una página de la historia de su pueblo y de la suya propia. La que va a escribirse colectiva e individualmente la observarán con ilusión y la afrontarán con un decidido empuje, esperanzados de que en ambos niveles tendrá un carácter decisivo. La educación recibida en las etapas vitales e históricas ahora conclusas le habrán pertrechado, a sus ojos,

13 "A veces mi padre nos llevaba a mi hermano y a mi a pasear hacia la estacion; nos gustaba ver los trenes, el Arco de Ladrillo, a veces poníamos en las vías una moneda de cobre (una perra gorda) 0 un clavo largo, y quedaban aplastados; el clavo, como una pequeña espada [...] Me impresionaba el poder de las grandes locomotoras de vapor; Ios trenes tenían una fascinación para mi, con una mezcla de elegancia y misterio". Una vida ..., 20. "Y luego, en el fondo de la más densa oscuridad y sobre el sordo zumbido de la máquina proyectora, la figuración visual del ensueño: aquella apasionante serie de imágenes en blanco y negro -o en verde pálido y negro, cuando la escena acontecía en noche de luna- que nos contaba y ofrecía la simple inminente y nunca lograda victoria de una pesadilla de malos poderosos y astutos sobre un pufiadito de buenos animosos e inermes [...] Así veo yo ahora la sutil y apasionada operación que los episodios de "La mano que aprieta" iban efectuando en mi alma cuando ésta, pasada la sobria escena dominical, vivía su fugaz y ensoñador duemevela en una alcoba de la soriana calle de los Estudios". Una y diversa..., 147-49. 
con el mejor bagaje para vivir, fecunda y plenamente, una época de la Historia que se atisbaba crucial.

Fruto último de esta formación será la sociabilidad, el método y talante socráticos como fórmula de entendimiento entre los hombres. La buena voluntad, las zonas luminosas del pensar y el actuar de la mujer y el hombre son muy superiores a las fuerzas oscuras o rupturistas. La democracia es, por consiguiente, el régimen más adecuado para la convivencia.

Aunque alguno sufriera una cierta inflexión en esta anhelada andadura, todos nuestros autores serán fieles, sin reparar en costos ni sufrimientos personales, a los ideales que conformaron su pensamiento en la hora, primero del descubrimiento del mundo $y$, después, en la de las grandes opciones ${ }^{14}$.

14 Vid J. M. CUENCA TORIBIO, La guerra civil de 1936. Madrid, 1986. Con grandes reservas historiográficas no será tal vez ociosa la lectura del reciente ensayo de A. TRAPIELLO, Las armas y las letras. Literatura y guerra civil (1936-1939). Madrid, 1994.

Aficiones y devociones en el antiguo régimen

Hispania Sacra 50 (1998) 